\title{
Complications as poor prognostic factors in patients with hemorrhagic stroke: A hospital-based stroke registry
}

\author{
Rizaldy Taslim Pinzon, Vincent Ongko Wijaya \\ Faculty of Medicine, Duta Wacana Christian University, Yogyakarta, Indonesia
}

\begin{abstract}
Introduction. Stroke patients commonly experience various medical complications during their rehabilitation stay. Understanding complications in hemorrhagic stroke patients can determine the patients prognosis.

Aim. This study aimed to explore complications as prognostic factors among patients with hemorrhagic stroke. Methods. This was an observational analytic study with retrospective design. We analyzed the medical records of 480 patients admitted with hemorrhagic stroke between 2017 and 2018 at Bethesda Hospital, Indonesia. Disability, mortality, and length of stay (LoS) were assessed as clinical outcomes for this study. Multivariate logistic regression was used to analyze the data

Results. The data were obtained from 480 patients with hemorrhagic stroke that majority of males $(58.5 \%)$, with $\leq 60$ years old $(52.3 \%)$, stroke onset $>3$ hours $(87.5 \%)$, and had stroke for the first time $(82.9 \%)$. The most common complications was $\mathrm{GI}$ tract bleeding $(19.8 \%)$, whereas the least was decubitus ulcer $(1.5 \%)$. There were $25.8 \%$ patients died during hospitalization period. Among 356 survivors, there were no significant prognosis factors of disability in subjects. Logistic regression found stroke onset $\geq 3$ hours (OR: $0.34 ; 95 \% \mathrm{Cl}: 0.19-0.59 ; \mathrm{p} \leq 0.001)$ and $\mathrm{Gl}$ tract bleeding (OR: $30.8 ; 95 \% \mathrm{Cl}: 16.93-55.88 ; \mathrm{p} \leq 0.001)$ to be an independent predictors of mortality in hemorrhagic stroke, whereas GI tract bleeding (OR: $0.54 ; 95 \% \mathrm{Cl}: 0.31-0.95 ; p=0.03$ ) and UTI (OR: 4.73; 95\%Cl: 1.11-20.1; $p=0.04$ ) were also an independent predictors of prolonged length of stay in hemorrhagic stroke.

Conclusion. This study identify complications as prognostic factors in hemorrhagic stoke patients. Stroke onset $>3$ hours, GI tract bleeding, and UTI were independent predictors of poor prognosis in hemorrhagic stroke. There were no prognosis factor that affects disability in subjects.
\end{abstract}

Keywords: hemorrhagic stroke, complication, prognosis, mortality, disability, length of stay

\section{BACKGROUND}

Stroke is one of the most important causes of global morbidity and mortality. In 2013, stroke was ranked second as the most common cause of death, responsible for 6.5 million deaths globally and the third most common cause of disability in the world. According to the latest world health organization (WHO) data published in 2017, stroke was the leading cause of death in Indonesia reached 332,663 or $19.79 \%$ of total deaths of the country. Stroke patients commonly experience medical complications such as pneumonia, urinary infection, decubitus, falls, deep vein thrombosis, and constipation from their rehabilitation stay. These complications may disrupt rehabilitation process and have been associated with increased mortality (1-4).

Stroke can be divided into 2 main types, which are ischaemic and hemorrhagic stroke. Patients who suffer ischemic strokes have a tendency of better chance for survival than those who experience hemorrhagic strokes, as hemorrhagic stroke not only damages brain cells but also may lead to increased pressure on the brain. There are two types of hemorrhagic stroke, which are intracerebral hemorrhagic (ICH) and subarachnoid hemorrhagic (SAH). Past study showed that, intracerebral hemorrhagic (ICH), a subtype of hemorrhagic stroke, predicted poor neurologic outcome of long-term disability and higher mortality as compared to ischemic stroke $(5,6)$. 
Stroke survivors present more further challenges in rehabilitation because most strokes occur with other serious medical diagnoses or comorbidity, which increase the stroke survivors tendency for developing medical complications during their rehabilitation stay. Unlike many patients seen in rehabilitation units, stroke survivors are more likely in older age and to have other chronic medical conditions. Many stroke survivors with complications can affect the patients prognosis during their hospitalization, which leads to more complex management in attempt to control risk factors and prevent recurrent strokes (7).

The high incidence of disability and mortality in hemorrhagic stroke requires special attention, therefore managing complications on hemorrhagic strokes can be challenging in order to prevent undesirable effects and jeopardise clinical outcomes. Previous study revealed that the presence of complications was the most predictive factors of disability in ischemic stroke. However, little is known about the association of medical complications with hemorrhagic stroke prognosis (8).

This study presents a new study on hemorrhagic stroke complications as the patients prognostic factor, assessed from 3 different clinical outcomes. To the best of our knowledge, this is the first study in Indonesia to identify complications as prognostic factors among patients with hemorrhagic stroke.

\section{AIM}

The aim of this study was to identify and explore various medical complications as prognostic factors among hemorrhagic stroke patients

\section{MATERIALS AND METHODS}

\section{Study design}

This was an observational retrospective study from the period of 2017 to 2018 at Bethesda Hospital, a large tertiary hospital with an established stroke center in Yogyakarta, Indonesia. According to the latest data in 2018 by Indonesian Health Ministry, Yogyakarta was ranked second highest for the stroke prevalence rate of all provinces of the country (9).

480 subjects admitted for hemorrhagic stroke who fulfilled the inclusion and exclusion criteria were enrolled in this study. Each subject recruited from the acute stroke intensive care unit had been followed up from the first day of hospitalized until they were discharged from the hospital (died or discharged alive). All data were obtained and recorded in the electronic stroke registry of Bethesda Hospital.

\section{Subjects selection}

480 subjects recruited using consecutive sampling, where sampling based on all subjects who met the inclusion criteria within a certain period of time in this study. The inclusion criteria in this study were (i) subjects diagnosed with hemorrhagic stroke, (ii) hospitalized at stroke care unit Bethesda Hospital, Yogyakarta, Indonesia, (iii) hospitalized between a period of 2017 to 2018, and (iv) subjects data had been recorded in the electronic stroke registry of Bethesda Hospital. The exclusion criteria were: (i) incomplete or missing data

This study received approval from the Ethical Committee of Medical Research of Duta Wacana Christian University and conducted in accordance with the ethical standards, laid down in the 1964 Declaration of Helsinki and its later amendments.

\section{Measurements and outcomes}

The hemorrhagic stroke diagnosis was made by emergency department physicians or neurologists during the first visit after admission, based on clinical symptoms. Non-contrast computed tomography (CT) scan was performed and interpreted by a neurologist or radiologist in order to confirm the diagnosis of hemorrhagic stroke. Patients with diagnosis of subarachnoid hemorrhagic (SAH) and intracerebral hemorrhagic (ICH) are included as hemorrhagic stroke patients in this study.

Subjects were assigned into two groups based on each outcome: (i) disability status, (ii) length of stay, and (iii) mortality status. The clinical variables were gender, age, stroke history, stroke onset, presence of comorbidity, and presence of complications (e.g. urinary tract infection, pneumonia, gastrointestinal tract bleeding, and decubitus ulcer).

Based on age, the subjects were grouped into those with age $\leq 60$ years old and $>60$ years old. Based on stroke history, the subjects were divided into those with first-time stroke and those with re- 
current stroke, and based on stroke onset the subjects were grouped into those with an onset of $<3$ hours and those with an onset of $\geq 3$ hours.

Based on comorbidity the subjects were differentiated into subjects with comorbidity and without comorbidity. Comorbidities assessed in this study included patient with medical history of type 2 diabetes mellitus (DM2), hypertension, dyslipidemia, ischemic heart disease (IHD), and atrial fibrillation on admission.

Complications assessed in this study included urinary tract infection (UTI), pneumonia, gastrointestinal bleeding, and decubitus ulcer that occurs during hospitalisation. UTI was defined as an infection in the urinary tract during hospitalization, confirmed by physical examination and urinalysis. Pneumonia was defined as pulmonary infection confirmed by physical examination, blood test, and chest radiograph. Gastrointestinal bleeding was defined as any episode of bleeding materials in nasogastric aspirate, hematemesis or melena as one of the the symptom. Decubitus ulcer was defined as any change in the color of the skin and the presence of a wound in the skin and underlying soft tissues covering bony areas compromized by pressure, especially in bed rest patients.

Disability is a limitation in performing functional activities and tasks on an acceptable level of social norm and on this basis the subjects were grouped into those without disability and those with disability. Disability status on this study was measured using modified Rankin score (mRS) scale to measure functional recovery and global functional independence at discharge. The $\mathrm{mRS}$ is a simple, efficient clinician-reported index of global disability and oftenly used in large-scale trials. Subjects without disability included subjects who were independent without any sequelae and no significant disability (mRS score 0 and 1 ). Subjects with disability included subjects with moderate disability, moderately severe disability, and severe disability with a home care program (mRS score 2 to 5). Subjects who died during their hospitalization stay (mRS score 6) were excluded from this assessment $(10,11)$.

Based on mortality status the subjects were divided into subjects who died and those who live during their hospitalization stay. The LoS was as- sessed as the period from the admission date to the date of separation (death or discharged alive). Based on length of stay during hospitalization stay, the subjects were divided into subjects with length of stay $<10$ days and $\geq 10$ days.

\section{Statistical analysis}

Descriptive analysis was performed to present the subjects characteristics. Bivariate analysis using chi-square test was conducted by analyzing between disability, mortality (among the survivors), length of stay (LoS) status with gender, age, stroke history, stroke onset, presence of comorbidity, and presence of complications (e.g. urinary tract infection, pneumonia, gastrointestinal tract bleeding, and decubitus). Multiple logistic regression analysis was performed to determine the independent predictive factor(s) of disability, mortality, and length of stay (LoS). Statistical significance was set at $\mathrm{p}<0.05$.

\section{RESULTS}

\section{Subjects characteristics}

A total of 480 patients were recruited for this study, among them 124 (25.8\%) had died during hospitalization period. Males represented 281 (58.5\%) cases than females. Table 1 presents the characteristics and clinical features of the patients. Most patients were $\leq 60$ years old $(52.3 \%)$, had stroke for the first time $(82.9 \%)$, stroke onset $\geq 3$ hours $(87.5 \%)$, and had no comorbidity ( $89 \%)$. The most common complications during hospitalization period were GI tract bleeding (19.8\%), followed by pneumonia $(2.7 \%)$, urinary tract infection $(1.7 \%)$, and the least was decubitus ulcer (1.5\%). Among the survivors, most patients had disability (95.5\%). Most patients stayed for $<10$ days $(73.3 \%)$ during hospitalization period.

TABLE 1. Characteristics and clinical features of the subjects

\begin{tabular}{|l|c|c|}
\hline Charateristic & Amount (n) & Percentage (\%) \\
\hline Gender & 281 & $58.5 \%$ \\
\hline Male & 199 & $41.5 \%$ \\
\hline Female & 251 & $52.3 \%$ \\
\hline Age & 229 & $47.7 \%$ \\
\hline$\leq 60$ years &
\end{tabular}




\begin{tabular}{|c|c|c|}
\hline Charateristic & Amount (n) & Percentage (\%) \\
\hline \multicolumn{3}{|l|}{ Stroke history } \\
\hline First stroke & 398 & $82.9 \%$ \\
\hline Recurrent stroke & 82 & $17.1 \%$ \\
\hline \multicolumn{3}{|l|}{ Stroke onset } \\
\hline$<3$ hours & 60 & $12.5 \%$ \\
\hline$\geq 3$ hours & 420 & $87.5 \%$ \\
\hline \multicolumn{3}{|l|}{ Comorbidity } \\
\hline Yes & 53 & $11 \%$ \\
\hline No & 427 & $89 \%$ \\
\hline \multicolumn{3}{|l|}{ Complications } \\
\hline \multicolumn{3}{|c|}{ Urinary tract infection } \\
\hline Yes & 8 & $1.7 \%$ \\
\hline No & 472 & $98.3 \%$ \\
\hline \multicolumn{3}{|l|}{ Pneumonia } \\
\hline Yes & 13 & $2.7 \%$ \\
\hline No & 467 & $97.3 \%$ \\
\hline \multicolumn{3}{|l|}{ GI tract bleeding } \\
\hline Yes & 95 & $19.8 \%$ \\
\hline No & 385 & $80.2 \%$ \\
\hline \multicolumn{3}{|l|}{ Decubitus ulcer } \\
\hline Yes & 7 & $1.5 \%$ \\
\hline No & 473 & $98.5 \%$ \\
\hline \multicolumn{3}{|l|}{ Disability (356) } \\
\hline Yes & 340 & $95.5 \%$ \\
\hline No & 16 & $4.5 \%$ \\
\hline \multicolumn{3}{|l|}{ Mortality } \\
\hline Died & 124 & $25.8 \%$ \\
\hline Live & 356 & $74.2 \%$ \\
\hline \multicolumn{3}{|c|}{ Length of stay (days) } \\
\hline$<10$ & 352 & $73.3 \%$ \\
\hline$\geq 10$ & 128 & $26.7 \%$ \\
\hline
\end{tabular}

Table 2 presents the prognostic factors of disability in patients with hemorrhagic stroke. Among 356 survivors, there were no factors that influenced the prognostic factor of disability in hemorrhagic stroke patients. Figure 1 identifies and compares the distribution between post-stroke complications and disability. Descriptively, all subjects with complications had disability. On the contrary, almost all of the subjects without complications also had disability and was in the range from $95.3 \%$ to $95.4 \%$.

Table 3 presents the prognostic factors of mortality in patients with hemorrhagic stroke. Based on the analysis, the strongest factor that influenced the prognostic factor of mortality in hemorrhagic stroke patients were GI tract bleeding (OR: 30.8; 95\%CI: $16.9-55.9 ; \mathrm{p} \leq 0.001)$, followed by stroke onset: $\geq 3$ hours (OR: 0.34; 95\%CI: 0.19-0.59; $\mathrm{p} \leq 0.001$ ), and patients aged $>60$ years (OR: 1.68; 95\%CI: 1.11-2.54; $\mathrm{p}=0.013$ ). Figure 2 identifies and compares the distribution between post-stroke complications and mortality. Descriptively, the most common subjects died during hospitalization were patients with GI tract bleeding (81.1\%), whereas the most least were patients with UTI $(0 \%)$.

Table 4 presents the prognostic factors of length of stay in patients with hemorrhagic stroke. Based on bivariate analysis, the strongest factor that influenced the prognostic factor of length of stay in hemorrhagic stroke patients were urinary tract infection (OR: 4.73; 95\%CI: 1.11-20.1; $\mathrm{p}=0.021$ ), followed by GI tract bleeding (OR: 0.54; 95\%CI: $0.31-0.95 ; p=0.031$ ). Figure 3 identifies and compares the distribution between post-stroke complications and length of stay. Descriptively, the most common subjects spent $\geq 10$ days length of stay were patients with UTI $(62.5 \%)$. Whereas, the most least were patients with GI tract bleeding (17.9\%).

Bivariate analysis was followed by multiple logistic regression analysis (table 5), which showed that onset $\geq 3$ hours (OR:0.34; 95\% CI: 0.19-0.59; $\mathrm{p} \leq 0.001)$ and GI tract bleeding (OR:30.8; 95\% CI:16.93-55.88; $\mathrm{p} \leq 0.001)$ were independent prognostic factors of mortality. The presence of GI tract

TABLE 2. Prognostic factors of disability in patients with hemorrhagic stroke

\begin{tabular}{|l|c|c|c|c|c|}
\hline Characteristics & $\begin{array}{c}\text { With Disability } \\
\mathbf{N}(\%)\end{array}$ & $\begin{array}{c}\text { Without Disability } \\
\mathbf{N}(\%)\end{array}$ & OR & $\mathbf{9 5 \%} \mathbf{C l}$ & p-value \\
\hline Gender: Male & $198(95.2)$ & $10(4.8)$ & 0.84 & $0.30-2.36$ & 0.735 \\
\hline Age: > 60 years & $154(97.5)$ & $4(2.5)$ & 2.48 & $0.79-7.86$ & 0.110 \\
\hline $\begin{array}{l}\text { Stroke history: Recurrent } \\
\text { stroke }\end{array}$ & $55(94.8)$ & $3(5.2)$ & 0.84 & $0.23-3.03$ & 0.785 \\
\hline Onset: $\geq 3$ hours & $311(96)$ & $13(4)$ & 2.48 & $0.67-9.19$ & 0.162 \\
\hline Comorbidity: Yes & $42(100)$ & $0(0)$ & 1.05 & $1.03-1.08$ & 0.134 \\
\hline Urinary tract infections: Yes & $8(100)$ & $0(0)$ & 1.05 & $1.02-1.07$ & 0.535 \\
\hline Pneumonia: Yes & $7(100)$ & $0(0)$ & 1.05 & $1.02-1.07$ & 0.562 \\
\hline GI tract bleeding: Yes & $18(100)$ & $0(0)$ & 1.05 & $1.03-1.08$ & 0.345 \\
\hline Decubitus ulcer: Yes & $5(100)$ & $0(0)$ & 1.05 & $1.02-1.07$ & 0.625 \\
\hline
\end{tabular}




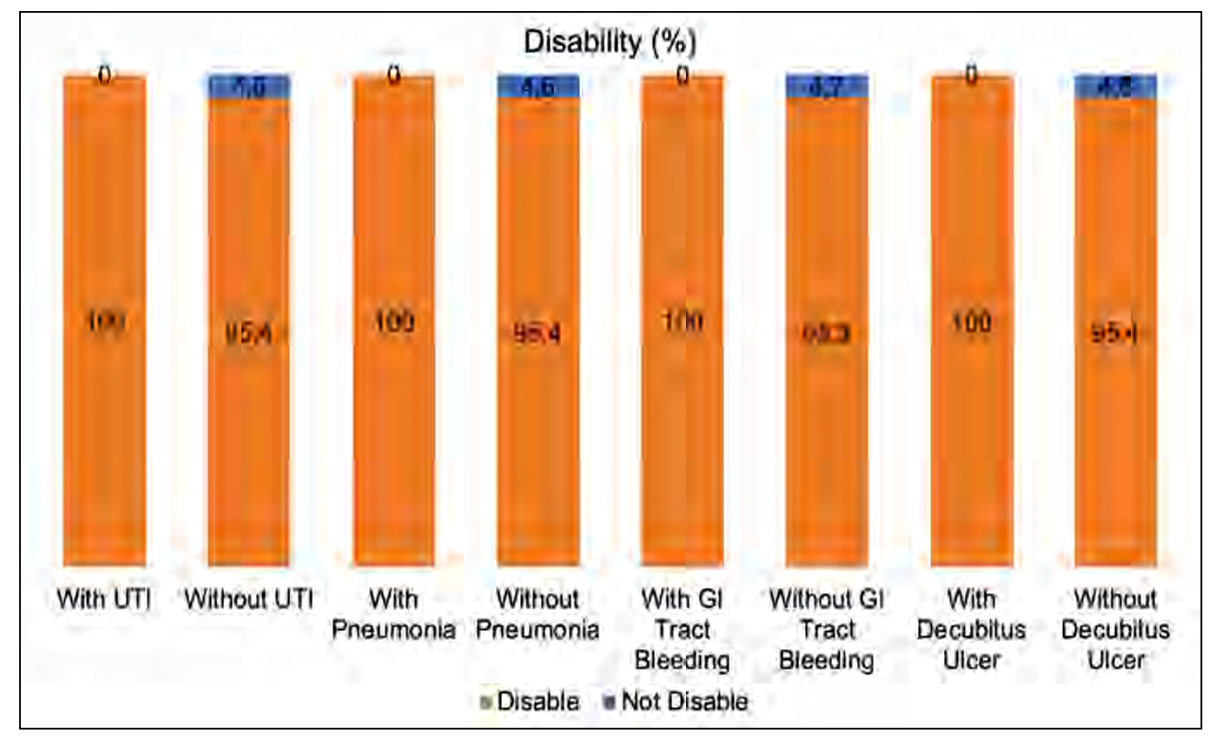

FIGURE 1. Distribution of disability among post-stroke complications

TABLE 3. Prognostic factors of mortality in patients with hemorrhagic stroke

\begin{tabular}{|l|c|c|c|c|c|}
\hline Characteristics & $\begin{array}{c}\text { Died } \\
\text { N (\%) }\end{array}$ & $\begin{array}{c}\text { Live } \\
\mathbf{N}(\%)\end{array}$ & OR & 95\% Cl & p-value \\
\hline Gender: Male & $73(26)$ & $208(74)$ & 1.02 & $0.67-1.54$ & 0.931 \\
\hline Age: $>60$ years & $71(31)$ & $158(69)$ & 1.68 & $1.11-2.54$ & 0.013 \\
\hline $\begin{array}{l}\text { Stroke history: } \\
\text { Recurrent stroke }\end{array}$ & $24(29.3)$ & $58(70.7)$ & 1.23 & $0.73-2.09$ & 0.435 \\
\hline Onset: $\geq 3$ hours & $96(22.9)$ & $324(77.1)$ & 0.34 & $0.19-0.59$ & $£ 0.001^{*}$ \\
\hline Comorbidity: Yes & $11(20.8)$ & $42(79.2)$ & 0.73 & $0.36-1.46$ & 0.370 \\
\hline Urinary tract infections: Yes & $0(0)$ & $8(100)$ & 1.36 & $1.29-1.43$ & 0.092 \\
\hline Pneumonia: Yes & $6(46.2)$ & $7(53.8)$ & 2.54 & $0.84-7.69$ & 0.090 \\
\hline Gl tract bleeding: Yes & $77(81.1)$ & $18(18.9)$ & 30.8 & $16.9-55.9$ & $£ 0.001^{*}$ \\
\hline Decubitus ulcer: Yes & $2(28.6)$ & $5(71.4)$ & 1.15 & $0.22-6.1$ & 0.868 \\
\hline
\end{tabular}

$* p<0.05$

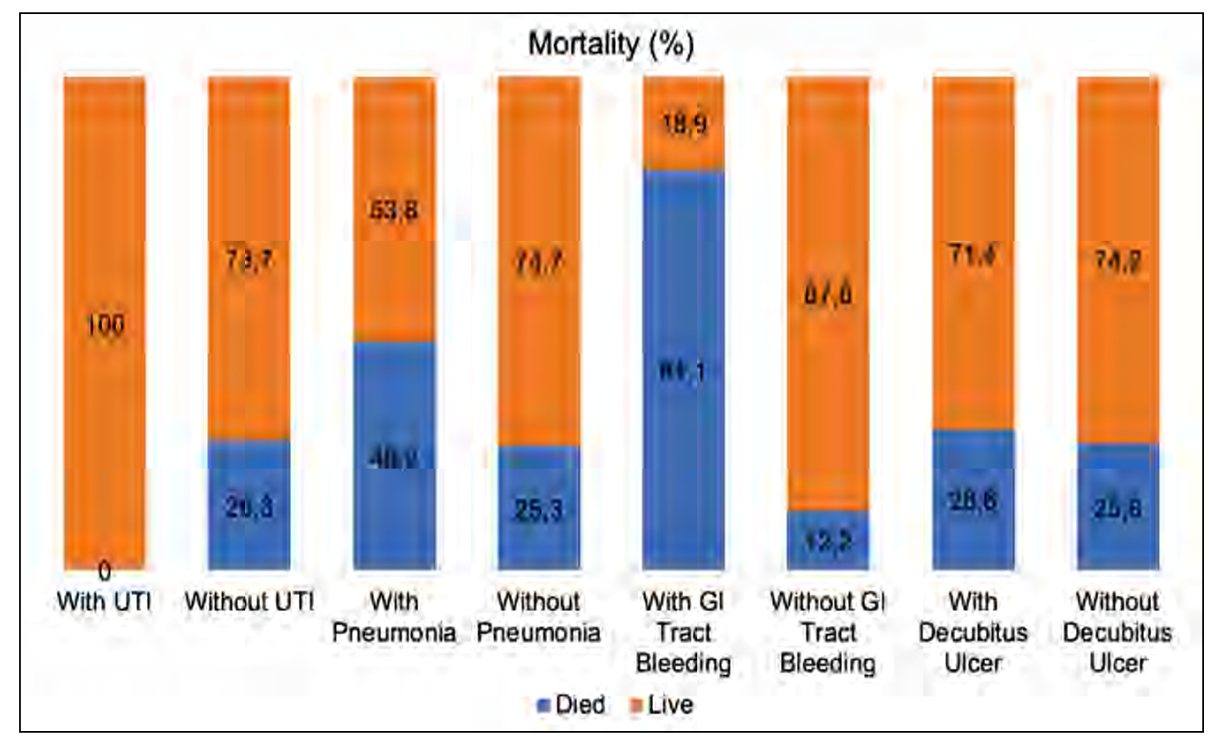

FIGURE 2. Distribution of mortality among post-stroke complications 
TABLE 4. Prognostic factor of length of stay in patients with hemorrhagic stroke

\begin{tabular}{|l|c|c|c|c|c|}
\hline Characteristics & $\begin{array}{c}\mathbf{1} \mathbf{1 0} \text { days } \\
\mathbf{N}(\%)\end{array}$ & $\begin{array}{c}<\mathbf{1 0} \text { days } \\
\mathbf{N}(\%)\end{array}$ & OR & $\mathbf{9 5 \%} \mathbf{~ C l}$ & p-value \\
\hline Gender: Male & $210(74.7)$ & $71(25.3)$ & 0.84 & $0.56-1.27$ & 0.410 \\
\hline Age: $>60$ years & $172(75.1)$ & $57(24.9)$ & 0.84 & $0.56-1.26$ & 0.401 \\
\hline Stroke history: Recurrent stroke & $20(24.4)$ & $62(75.6)$ & 0.87 & $0.50-1.50$ & 0.609 \\
\hline Onset: $\geq 3$ hours & $115(27.4)$ & $305(72.6)$ & 1.36 & $0.71-2.61$ & 0.349 \\
\hline Comorbidity: Yes & $13(30.2)$ & $40(69.8)$ & 0.88 & $0.46-1.71$ & 0.709 \\
\hline Urinary tract Infections: Yes & $3(37.5)$ & $5(62.5)$ & 4.73 & $1.11-20.1$ & $0.021^{*}$ \\
\hline Pneumonia: Yes & $6(46.2)$ & $7(53.8)$ & 2.42 & $0.80-7.35$ & 0.107 \\
\hline GI tract bleeding: Yes & $17(17.9)$ & $78(82.1)$ & 0.54 & $0.31-0.95$ & $0.031^{*}$ \\
\hline Decubitus Ulcer: Yes & $4(57.1)$ & $3(42.9)$ & 3.75 & $0.83-17.0$ & 0.066 \\
\hline
\end{tabular}

$* p<0.05$

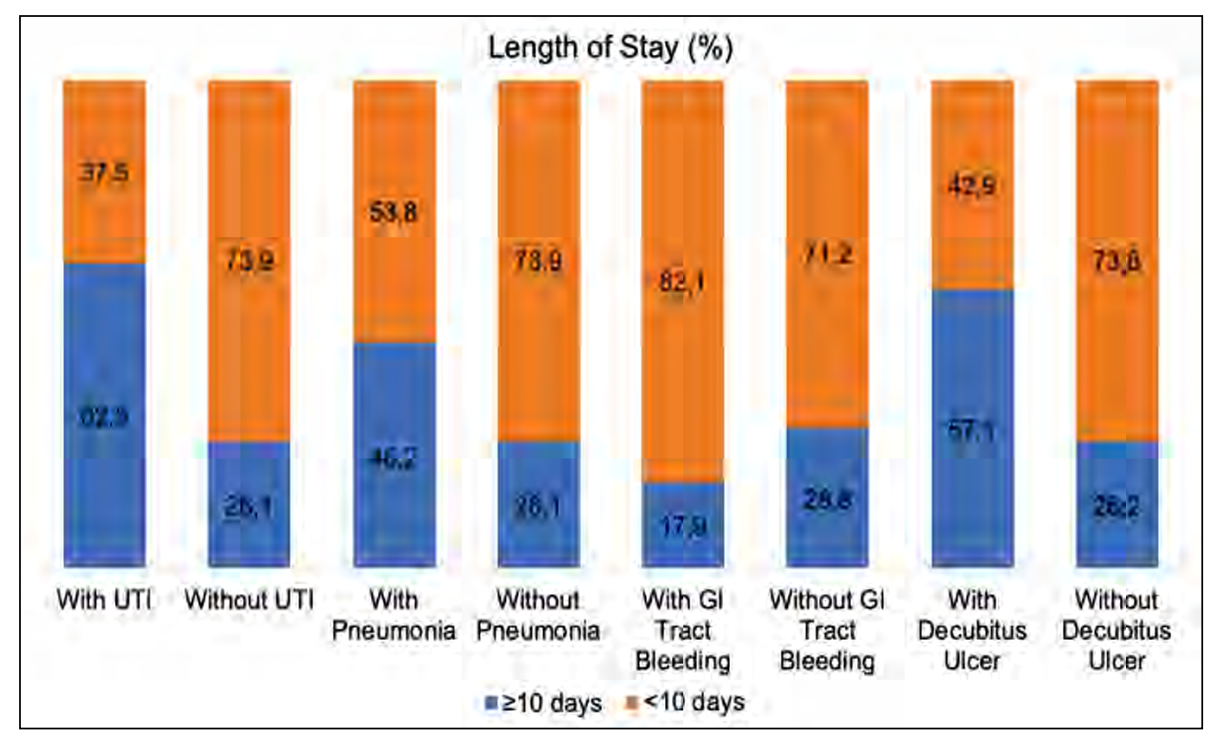

FIGURE 3. Distribution of length of stay among post-stroke complications

TABLE 5. Factors associated with the risk of poor prognostic by multiple logistic regression

\begin{tabular}{|c|c|c|c|c|}
\hline \multicolumn{5}{|c|}{ Mortality } \\
\hline & $\begin{array}{c}\text { Died } \\
(n=124)\end{array}$ & $\begin{array}{c}\text { Live } \\
(n=356)\end{array}$ & P-value & OR $(95 \% \mathrm{Cl})$ \\
\hline \multicolumn{5}{|c|}{ Stroke onset } \\
\hline$\geq 3$ hours & $96(22.9 \%)$ & $324(77.1 \%)$ & $<0.001$ & $0.34(0.19-0.59)$ \\
\hline$<3$ hours & $28(46.7 \%)$ & $32(53.3 \%)$ & & \\
\hline \multicolumn{5}{|c|}{ GI tract bleeding } \\
\hline Yes & 77 (81.1\%) & $18(18.9 \%)$ & $<0.001$ & $30.8(16.93-55.88)$ \\
\hline \multirow[t]{2}{*}{ No } & $47(12.2 \%)$ & $338(87.8 \%)$ & & \\
\hline & $\begin{array}{c}\geq 10 \text { days } \\
(n=128)\end{array}$ & $\begin{array}{l}<10 \text { days } \\
(n=352)\end{array}$ & P-value & OR (95\%Cl) \\
\hline \multicolumn{5}{|r|}{ Urinary tract infection } \\
\hline Yes & $5(62.5 \%)$ & $3(37.5 \%)$ & 0.04 & $4.73(1.11-20.1)$ \\
\hline No & $123(26.1 \%)$ & $349(73.9 \%)$ & & \\
\hline \multicolumn{5}{|c|}{ GI tract bleeding } \\
\hline Yes & $17(17.9 \%)$ & $78(82.1 \%)$ & 0.03 & $0.54(0.31-0.95)$ \\
\hline No & $111(28.8)$ & $274(71.2 \%)$ & & \\
\hline
\end{tabular}

bleeding (OR:0.54; 95\%CI: 0.31-0.95; $\mathrm{p}=0.03$ ) and UTI (OR:4.73; 95\%CI: 1.11-20.1; $\mathrm{p}=0.04$ ) were independent prognostic factors of prolonged length of stay. 


\section{DISCUSSION}

The effect of medical complications as prognostic factor on ischemic stroke or other traumatic brain injury have been well established. However, less is known about hemorrhagic stroke. The aim of this study was to identify medical complications and other factors as prognostic factors among hemorrhagic stroke patients. In this cross-sectional study, majority of subjects were males. This is consistent with studies from Asia and Australia, showed that males were more susceptible to hemorrhagic stroke than women $(12,13)$.

The results indicated that the overall prevalence of stroke in adults aged $\leq 60$ years was $52.3 \%$. In contrast, an epidemiology study by American Heart Association reported that prevalence and annual rate of first time stroke is increases sharply with age. Most of the subjects in this study had stroke for the first time $(82.9 \%)$. In 2015 , about 795,000 people in the United States suffered a new or recurrent stroke and approximately 610,000 of these were first events (14).

53 patients $(11 \%)$ had comorbidity on admission, our study revealed that the presence of comorbidity was not statistically significant as prognostic factor of hemorrhagic stroke. One study from Cameroon showed that comorbid medical conditions did not influence outcome after intracerebral hemorrhagic (16).

The association between post-hemorrhagic stroke complications and clinical outcomes have been uncertain. Therefore, we measured the patients outcomes based on disability, mortality, and length of stay.

Of the 584 hemorrhagic stroke survivors, 356 (95.5\%) had disability, which is higher than the range (45-71\%) reported in a nationwide surveys in China and Western countries. Variation between these studies may relatively be associate with differences in definitions of disability and instruments to assess disability (e.g. Barthel Index, mRS), length of follow up, post-stroke illness stage and sample size $(17,18)$.

Statistical analyses revealed that male gender, age $>60$ years old, previous history of recurrent stroke, stroke onset $\geq 3$ hours, presence of comorbidity, and medical complications during hospitalization were not significantly associated with poststroke disability. In contrary, a recent study from
Thailand revealed that age $>60$ years old, male gender, consciousness during admission, hypertension, and infection were significant predictors of disability in patients with hemorrhagic stroke.

The hospital mortality rate was $25.8 \%$. A hospital-based study in Africa reported a similar result to the current study of $26.8 \%$ mortality in hemorrhagic stroke. Recent multicenter Asiatic study similar to the current study reported $12.5 \%$ post-stroke mortality rates and another study that included both ischaemic and haemorrhagic stroke reported hospital mortality rates was $16 \%$. The differences between the mortality rates around the world could be linked to the different quality of the nation health system including the delays in management and access to healthcare facility $(16,19,20)$.

In our study, the non-infectious complications during hospitalization period were GI tract bleeding $(19.8 \%)$, and decubitus ulcer $(1.5 \%)$. With regard to infectious diseases, pneumonia and urinary tract infection (UTI) occurred in $2.7 \%$ and $1.7 \%$ of patients, respectively. One multicenter study reported that internal medical complications occurred in $85 \%$ of patients with acute stroke. Another study comparing ischaemic and hemorrhagic stroke found that the common complications related to post-hemorrhagic stroke, occured during the rehabilitation period were pneumonia $(6.72 \%)$, urinary tract infection $(4.96 \%)$, bowel dysfunction $(10.26 \%)$, and pressure sore $(0.69 \%)(20,21)$.

Multiple logistic regression model showed that stroke onset $\geq 3$ hours and GI tract bleeding were significant predictors of mortality in patients with hemorrhagic stroke.

In intracerebral hemorrhagic, initial vessel rupture followed by hematoma causes direct mechanical injury to the brain parenchyma. Perihematomal edema develops within the first 3 hours from symptom onset and peaks between 10 to 20 days, this explains why the stroke onset was correlated with poor outcome. Our study appear to confirm previous studies that showed gastrointestinal bleeding has a significant effect on acute stroke morbidity and mortality $(22,23)$.

Our findings suggest that UTI and GI tract bleeding complications were a significant risk factor for prolonged length of stay. Past study has discovered that the prevalence of GI bleeding after ICH was $26.7 \%$ and patients with GI bleeding had 
significantly longer hospital stay and higher in-hospital mortality compared with patients without GI bleeding. Another prospective study found some predictors of gastric haemorrhage included size of intracranial haematoma, sepsis and Glasgow Coma scores. Stress ulcer after ICH has been linked to be the major cause of GI bleeding. It is believed that the acute rise in intracranial pressure accompanying ICH may result in vagal hyperactivity and lead to increased gastric acid secretion or mucosal ischemia (24-26).

We found that post-stroke UTI increased the risk of prolonged length of stay. This finding is consistent with a recent cohort study of infection after cerebral hemorrhagic, that patients with post-stroke nosocomial infection was associated with worse outcomes. Other study, about post-stroke complications, suggests that Nosocomial infection was associated with longer hospital stay and a more than twofold higher cost of care. Post-stroke infection was strongly correlated with risk factors for infection such as poor GCS, intubation, dysphagia, pulmonary oedema, and invasive procedures. Potential mechanism include, infection may enhance pro-inflammatory cascades and causing a general activation of lymphocytes, might lead to secondary neuronal injury and worse functional outcomes after ICH (27-30).

The present study has the following limitation. First, the characteristics of stroke such as size and location of bleeding were not included in this study due to lack of data in the medical record; consequently, the relationship between severity of stroke and the complications cannot be predicted. Second,

\section{REFERENCES}

1. Feigin VL, Norrving B, Mensah GA. Global Burden of Stroke. Circ. Res. 2017, 120, 439-448.

2. Tran J, Norton R, Conrad N, Rahimian F, Canoy D, Nazarzadeh M, Rahimi K. Patterns and temporal trends of comorbidity among adult patients with incident cardiovascular disease in the UK between 2000 and 2014: A population-based cohort study. PLoS Med. 2018, 15, e1002513.

3. Ingeman A, Andersen G, Hundborg HH, Johnsen SP. Medical complications in patients with stroke: Data validity in a stroke registry and a hospital discharge registry. Clin Epidemiol. 2010;2:5-13.

4. World Health Organization. 2017. State of Health Inequality: Indonesia. Geneva.

5. Chiu D, Peterson L, Elkind MSV, Rosand J, Gerber LM, Silverstein MD. Comparison of outcomes after intracerebral hemorrhagic and ischemic stroke. Journal of Stroke and Cerebrovascular Diseases. 2010; 19(3):225-229. medical complications after discharge were not examined; therefore, the long-term effects of poststroke complications remains unclear. Further studies are required to determine the stroke severity and complications that associate with post-stroke recovery and seek measures to prevent the incidence of such complications.

Nevertheless, our study is significant in that it suggests an evaluation of the incidence of poststroke medical complications and the factors affecting these complications. This report thereby provides considerable analysis and key information on the association between factors affecting poststroke functional recovery especially complications and patients prognosis.

\section{CONCLUSIONS}

The majority of complications are preventable and treatable; therefore, early and appropriate care of patients with stroke can improved the functional outcomes. Our results should encourage physicians to be vigilant about prevention and treatment of post-stroke complications, especially GI tract bleeding and UTI.

\section{Acknowledgements}

This research was personally funded by the authors. The abstract of this research has been presented in World Congress of Neurology 2019 as Poster Presentation and has been named a finalist in the prestigious 2019 clinical research award of „Anugerah Karya Cipta Dokter Indonesia” held by Indonesian Physicians Association and Kalbe.

Conflict of interest: none declared Financial support: none declared

6. Keep RF, Hua Y, Xi G. Intracerebral haemorrhage: Mechanisms of injury and therapeutic targets. Lancet Neurol. 2012;11:720-731.

7. Ostwald SK, Wasserman J, Davis S. Medications, comorbidities, and medical complications in stroke survivors: The CAReS study. Rehabil Nurs. 2006;31(1):10-4

8. Pinzon RT, Sanyasi RDLR. Complications as important predictors of disability in ischemic stroke. Univ Med. 2017;36:197-204.

9. Indonesian Health Ministry. Basic Health Research. 2018.

10. Braz L. Scales in stroke patients: The modified Rankin scale. Int J Clin Neurosci Mental Health 2016;3 Suppl 1:L22.

11. Kasner SE. Clinical interpretation and use of stroke scales. Lancet Neurol. 2006; 5: 603-612.

12. Thrift AG, Dewey HM, Sturm JW, Srikanth VK, Gilligan AK, Gall SL et al. Incidence of stroke subtypes in the North East Melbourne Stroke Incidence Study (NEMESIS): differences between men and women. Neuroepidemiology. 2009;32(1):11-8. 
13. Hsieh JT, Ang BT, Ng YP, Allen JC, King NK. Comparison of Gender Differences in Intracerebral Hemorrhagic in a Multi-Ethnic Asian Population. PLoS One. 2016;11(4):e0152945.

14. Mozaffarian D, Benjamin EJ, Go AS, Arnett DK, Blaha MJ, Cushman M, de Ferranti S, Després JP, Fullerton HJ, Howard VJ, Huffman MD, Judd SE, Kissela BM, Lackland DT. Heart Disease and Stroke Statistics - 2015 Update. Circulation. 2015;131(4):e29-322.

15. Berlowitz DR, Hoenig H, Cowper DC, Duncan PW, Vogel WB. Impact of comorbidities on stroke rehabilitation outcomes: Does the method matter?. Arch Phys Med Rehabil. 2008 Oct;89(10):1903-6.

16. Mapoure NY, Tchaleu Nguenkam CB, Mbatchou Ngahane HB et al. Predictors of In-Hospital Mortality for Stroke in Douala, Cameroon. Stroke Research and Treatment, 2014.

17. Hankey GJ, Jamrozik K, Broadhurst RJ, Forbes S, Anderson CS. Long-term disability after first-ever stroke and related prognostic factors in the Perth Community Stroke Study, 1989-1990. Stroke. 2002; 33(4):1034-40.

18. Yang $\mathrm{Y}$, Shi $\mathrm{YZ}$, Zhang $\mathrm{N}$ et al. The Disability Rate of 5 -Year Post-Stroke and Its Correlation Factors: A National Survey in China. PLoS One. 2016;11(11):e0165341.

19. Wong KS. Risk factors for early death in acute ischemic stroke and intracerebral hemorrhagic: A prospective hospital-based study in Asia. Stroke 1999;30(11):2326-2330.

20. Langhorne P, Stott DJ, Robertson L, MacDonald J, Jones L, McAlpine $C$ et al. Medical complications after stroke: A multicenter study. Stroke. 2000;31:1223-1229.

21. Kim BR, Lee J, Sohn MK et al. Risk Factors and Functional Impact of Medical Complications in Stroke. Ann Rehabil Med. 2017; 41(5):753-760.
22. Aronowski J, Zhao X. Molecular pathophysiology of cerebral hemorrhagic: Secondary brain injury. Stroke. 2011;42(6):1781-6.

23. Davenport RJ, Dennis MS, Warlow CP. Gastrointestinal hemorrhagic after acute stroke. Stroke. 1996; 27(3):421-4.

24. Misra U, Kalita J, Pandey S, Mandal S. Predictors of gastrointestinal bleeding in acute intracerebral haemorrhage. Journal of the Neurological Sciences 2003;208(1-2):25-29.

25. Yang TC, Li JG, Yu DM, Shan K, Li LX, Dong XY, Shi HM. Gastrointestinal Bleeding After Intracerebral Hemorrhagic: A Retrospective Review of 808 Cases. The American Journal of the Medical Sciences. 2013;346(4):279-282.

26. Chan KH, Mann KS, Lai EC, et al. Factors influencing the development of gastrointestinal complications after neurosurgery: results of multivariate analysis. Neurosurgery 1989;25:378-82.

27. Lord $A S$, Langefeld $C D$, Sekar $P$ et al. Infection after intracerebral hemorrhagic: risk factors and association with outcomes in the ethnic/racial variations of intracerebral hemorrhagic study. Stroke. 2014;45(12):3535-3542.

28. Murthy SB, Moradiya Y, Shah J, et al. Nosocomial Infections and Outcomes after Intracerebral Hemorrhagic: A Population-Based Study. Neurocrit Care. 2016 Oct;25(2):178-84.

29. Ali M, Lyden P, Sacco RL, Shuaib A, Lees KR. Natural history of complications after intracerebral haemorrhage. Eur J Neurol. 2009; 16:624-630.

30. Ohwaki K, Yano E, Nagashima H, Nakagomi T, Tamura A. Impact of infection on length of intensive care unit stay after intracerebral hemorrhagic. Neurocrit Care. 2008;8:271-275. 